\title{
Maximizing the information yield from annually resolving natural archives
}

\author{
Bernd Zolitschka ${ }^{1}$ and Jennifer Pike ${ }^{2}$
}

Natural archives containing yearly information are impressive, not only esthetically (see cover picture) but also in terms of their scientific potential. They hold the key to bridging the divide between long but low-resolution paleoscience and short but detailed climatic and environmental monitoring. Annually layered archives theoretically can combine the best from both worlds by delivering long records at sub-annual resolution. In practice, however, reality often stands in the way by presenting considerable challenges that need to be overcome before producing paleorecords at monitoring quality. Therefore, researchers are working hard to improve methodologies and understanding in order to maximize the yield from annual-resolution archives, and we report in this magazine issue on some of the latest advances and their limitations.

\section{The Varves Working Group}

The potential of annually laminated (varved) sediments for developing detailed chronologies of past environmental change was recognized by geologists more than a century ago. However, methodological limitations in the handling of varved sediments and in developing quantitative paleoenvironmental interpretations established a perception of subjective and unreliable results. Since the end of the 20 th century, with the advent of new coring techniques and innovative analytical methods, varved records have now been established as an important resource for environmental and climatic research, and scientists are working towards seasonal resolution.

The PAGES Varves Working Group (VWG) is the nucleus for this magazine issue. The group was initiated in 2010 to maximize the gain from varved lacustrine and marine records in association with other annually resolving archives (tree rings, corals, bivalve shells, ice cores, speleothems). Since its inception, the VWG has addressed a number of topics including: methodological achievements; setting up the best possible varve chronologies including age uncertainties; calibration of inherent climatic and environmental signals; data management and processing. Additionally, learning from, and integrating, other annually resolved archives is crucial for developing an understanding of the past.

The VWG organized three dedicated, cross-disciplinary workshops to discuss cutting edge topics in high-resolution natural archives. These workshops were held in Lääne-Virumaa, Estonia (2010; Francus et al. 2010), Corpus Christi, USA (2011; Besonen et al. 2011) and Manderscheid, Germany (2012; Zolitschka et al. 2012). During this most recent workshop the idea of dedicating a PAGES magazine on year-to-year analysis of annually resolved natural archives was born. The following twelve articles document the state-of-the-art of the challenge of working at the highest temporal resolution and of harnessing a maximum of environmental and climatic information. An underlying research question for this PAGES magazine is: How can we use natural archives to approach the temporal resolution of instrumental records? Some of the articles address this by reporting on previous research (Lamoureux and Francus; St. George; Turney et al.; Liangcheng et al.), or new or advanced techniques (Nakagawa; Grosjean et al.; Rasmussen et al.), or new results (Ojala et al.; Kemp; Schöne and Surge; Fairchild et al.; Schwikowski et al.). Overall, the articles demonstrate that the process-level understanding of records has improved tremendously in recent years. Natural annual recorders can provide accurate reconstructions of past behavior of climate-system components on the robust and absolute timescales that are needed to better understand the mechanisms involved, and to test models of future change.

\section{Sediments (lacustrine, marine)}

The study of varved sediments is progressing quickly towards analyses at annual and seasonal resolution. High-precision depth control is a necessity for high-resolution studies. When using "destructive methods" that require sampling the sediment core, new cutting and subsampling techniques have been developed that enable core sectioning and parallel core correlation at annual resolutions. These new methods also correct for depth changes due to expansion and contraction during storage (Nakagawa et al.).

To reach sub-annual resolution, non-destructive scanning techniques such as element count-rates analyzed by micro-XRF scanning (Fig. 1) are often more effective. Another such method is hyperspectral imaging, which is used to identify organic components and minerals on the basis of their diagnostic light absorption. Not only is this method promising for lake and marine sediments but it is also applicable to tree rings and speleothems (Grosjean et al.).

Just as important as high-resolution chronology and analysis is the understanding of sediment-formation processes. Deposition of abiotic and biotic components can be monitored with sediment traps and time-series data used to calibrate varves and their paleolimnological proxies against instrumental data (Ojala et al.). Long-term monitoring with sediment traps in the Arctic has permitted the identification of quantitative processes that form varves and the documentation of the climate signals conveyed through runoff generation and downstream sediment transport. Thus, previously unrecognized hydroclimatic control mechanisms on sediment delivery are detectable (Lamoureux and Francus).

Marine varved sediments are not restricted to oxygen-depleted or silled basins, or to productive shelves and slopes. They are also found at deep-sea sites with massive particle fluxes that suppress benthic faunal activity and therefore preserve laminations. Thus, the traditionally centennial-resolution quantitative paleoceanographic reconstructions can be increased to annual or seasonal resolution using scanning electron microscope techniques. Moreover, stable isotopes derived from diatoms preserved within varves offer insights into dynamic processes of ocean-atmosphere variability on seasonal timescales (Kemp).

\section{Organisms (trees, bivalves)}

Tree-ring width records have been developed at thousands of locations, particularly in the Northern Hemisphere. Their broad regional coverage and extended replication forms the basis of a global network representing a valuable resource for high-resolution climate reconstruction (St. George). In the Southern Hemisphere relatively few tree-ring records are available but new methods are being developed in Australasia to exploit their potential in this region. Analytical advances can characterize wood at the level of single cells, enabling a detailed study of the role of environmental conditions in tree-ring formation. These wood-property chronologies are developed for samples without any seasonal signal in tree-ring width and thus demonstrate the paleoscientific potential of trees in regions where standard analyses have failed. Another exciting possibility in Australasia is radiocarbon 


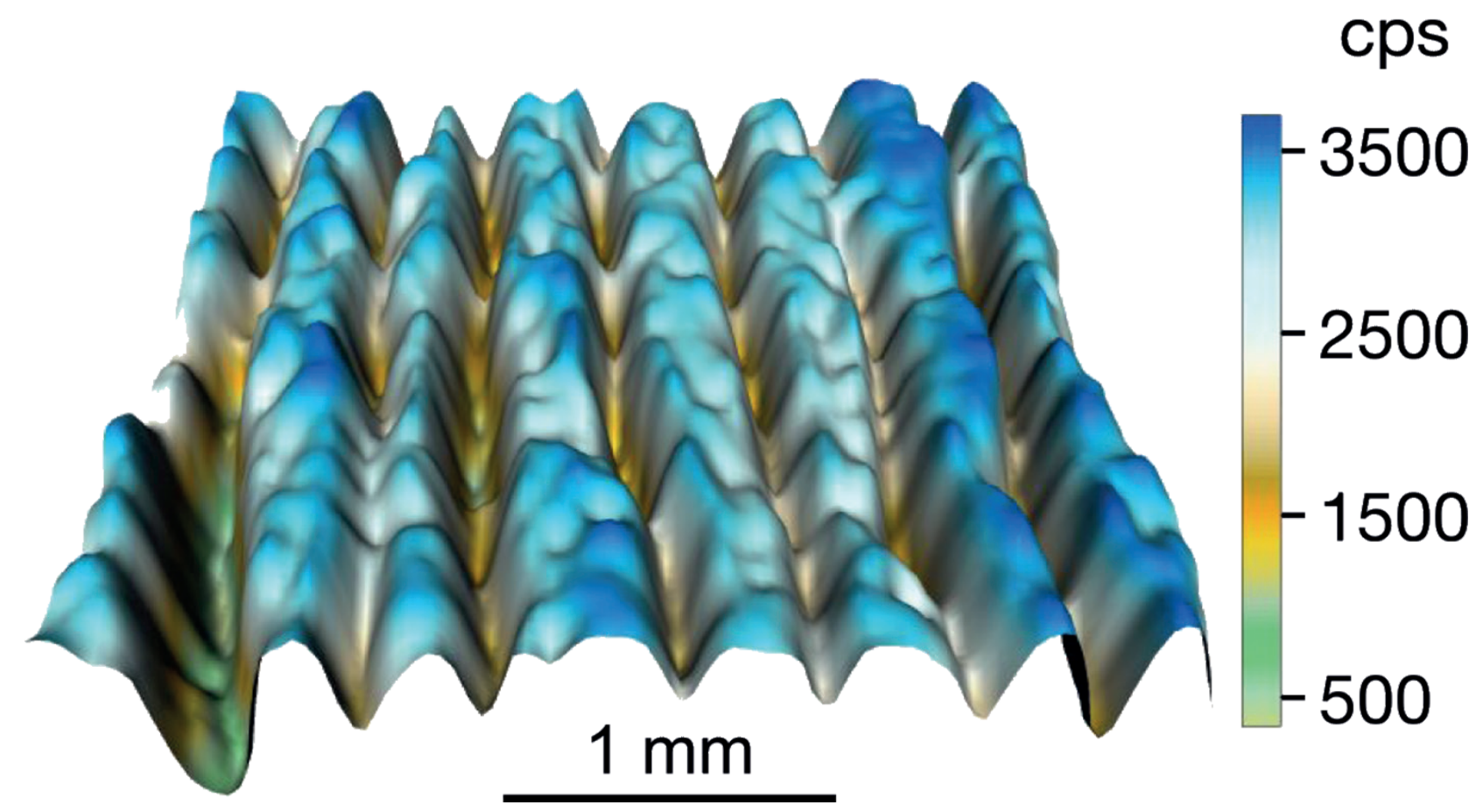

Figure 1: Micro-XRF elemental grid scan of a varved sediment section from the Piánico paleolake (Italy) documenting a subannual geochemical profile for the element Ca (image courtesy of Peter Dulski).

calibration using subfossil kauri trees from northern New Zealand that potentially cover the complete range of ${ }^{14} \mathrm{C}$ dating (Turney et al.).

Bivalves, present in many aquatic environments, can record environmental changes at unprecedented temporal resolution from years to days. Their individually short growth-increment chronologies can be combined by cross-dating segments with overlapping life spans of other individuals to develop composite chronologies covering millennia, while stable isotope data and elemental ratios provide process-driven environmental information (Schöne and Surge).

\section{Physical records from travertine and ice}

Calcareous cave deposits (speleothems) are common features in karst environments. Statistical analyses of their growth-rates reflect the mixing of rainfall with groundwater and are used to reconstruct hydroclimate and, more recently, annual temperature changes (Tan et al.). Seasonal climatic signals are transmitted to speleothems via the quantity, chemistry and isotopic composition of percolating water in caves. Advances in high-resolution measurements of stable isotopes, trace elements and organic fluorescence reveal sub-annual variations in speleothem chemistry that result not only in improved chronologies, but also in seasonal climatic and environmental changes (Fairchild et al.).

Polar ice caps provide a wealth of information on past climates and environments as well as a very accurate chronology through counting the annual layers. Historically, ice-core chronologies have relied on manually detecting and counting annual layers; however, the development of novel algorithms for automated and objective annual layer counting has allowed researchers to refine and extend these chronologies. Parallel analysis of different impurity records is also recommended to establish a robust chronology (Rasmussen et al.). High-mountain ice cores have the potential to provide subannual ice-core records; however, annual layer thinning with increasing depth increases dating uncertainties. While new continuous flow analysis-techniques are increasing the spatial resolution, calibration with instrumental data is often still restricted to multi-year resolution, which limits the potential of annual resolution from mountain glacier ice cores (Schwikowski et al.).

A major aim of the VWG is to connect research groups working on different annual archives, eventually leading towards integrated model-data comparisons at an annual to subannual scale. Products of the VWG include overview articles (Ojala et al. 2012; Francus et al. 2013) and the "Varves Image Library" (work in progress), providing easy access especially for young scientists to digital images of a wide range of varved sediments, the "Varve Data Base" (Ojala et al. 2012) with a large variety of data for well-published varved sequences, and the "Varves Literature Archive", a constantly updated and searchable text file with varve-related publications.

\section{LINKS}

Varves Image Library:

www.pages-igbp.org/workinggroups/varves$\mathrm{wg} /$ varve-image-library
Varves literature archive:

www.pages-igbp.org/download/docs/working_groups/vwg/Varve\%20publications.pdf

Varves database:

www.pages-igbp.org/workinggroups/ varves-wg\#data

\section{AFFILIATIONS}

${ }^{1}$ Institute of Geography, University of Bremen, Germany ${ }^{2} \mathrm{~S}$ chool of Earth and Ocean Sciences, Cardiff University, UK

\section{CONTACT}

Bernd Zolitschka: zoli@uni-bremen.de

\section{REFERENCES}

Besonen M et al. (2011) PAGESnews 19(2): 88-89 Francus P et al. (2010) PAGESnews 18(2): 90-91 Francus P et al. (2013) J Geol Soc Swe 135: 229-339 Ojala AEK et al. (2012) Quat Sci Rev 43: 45-60 Zolitschka B et al. (2012) PAGESnews 20(2): 95 